\title{
SKALA KECERDASAN SPIRITUAL REMAJA MUSLIM
}

\author{
Risma Nur Avita1, Adhystia Putri H², Milenia Qodariyah³, \\ Nawabika Izzah ${ }^{4}$, Achiel Yahya ${ }^{5}$ \\ 1,2,3,4,5 Universitas Islam Negeri Sunan Ampel Surabaya \\ nuravitarisma@gmail.com
}

\begin{abstract}
Spiritual intelligence is a combination of two intelligences, including intellectual intelligence and emotional intelligence. In this case, spiritual intelligence is a form of self-adjustment used in guiding individuals to have a meaningful life. According to WHO, what is called an adolescent is an individual who is in the transition stage from childhood to adulthood. When individuals want or are trying to improve spiritually, a deep understanding of Islam is needed, besides that it also improves the implementation of Islamic teachings. The research method on the spiritual intelligence scale of Muslim adolescents that we use is a quantitative research method. The subjects or participants who are targeted in this measuring instrument are Muslim teenagers who have an age range of 12 to 24 years. This measuring instrument has eight experts in the expert judgment stage. Then there are 104 Muslim adolescent respondents who have been willing to fill out and answer items regarding the spiritual intelligence scale. Based on the aspect of spiritual intelligence there are 78 items, then reduced to 26 items that are valid or good and responded well. Based on the alphacornbach score, it produces a value of 0.856. So it can be concluded that the spiritual intelligence scale of Muslim youth is worthy of being an instrument of measurement
\end{abstract}

Keywords: Spiritual Intelligence, Teenager, Moslem

\section{ABSTRAK}

Kecerdasan spiritual yakni gabungan antara dua kecerdasan, diantaranya yaitu kecerdasan intelektual dan juga kecerdasan emosional. Dalam hal ini kecerdasan spiritual merupakan salah satu bentuk penyesuaian diri yang digunakan dalam menuntun individu untuk memiliki kehidupan yang berarti. Menurut WHO, yang disebut dengan remaja adalah individu yang berada pada tahap perpindahan dari masa kanak-kanak kemasa dewasa. Ketika individu ingin atau berusaha meningkatkan spiritual, maka diperlukan pemahaman secara mendalam tentang islam, selain itu juga meningkatkan pelaksanaan ajaran islam. Metode penelitian dalam skala kecerdasan spiritual remaja muslim yang kami gunakan adalah metode penelitian kuantitatif. Adapun subjek atau partisipan yang menjadi sasaran dalam alat ukur ini yakni remaja muslim yang mempunyai umur dengan rentang 12 hingga 24 tahun. Alat ukur ini memiliki delapan ahli dalam tahap expert judgment. Kemudian terdapat 104 responden remaja muslim yang telah bersedia untuk mengisi dan menjawab item mengenai skala kecerdasan spiritual. Berdasarkan aspek kecerdasan spiritual terdapat 78 item, kemudian direduksi menjadi 26 item yang valid atau bagus dan direspon dengan baik. Berdasarkan skor alpha-cornbach menghasilkan nilai sebesar 0,856. Jadi dapat disimpulkan bahwa skala kecerdasan spiritual remaja muslim ini layak untuk dijadikan instrumen pengukuran.

Kata Kunci: Kecerdasan Spiritual, Remaja, Muslim

\section{Pendahuluan}

WHO memaparkan bahwa remaja ialah suatu individu yang ada pada masa perpindahan fase kanak-kanak \& dewasa. WHO juga menyatakan bahwa kategori umur remaja sendiri ialah 12 tahun hingga 24 tahun. Fase remaja adalah fase dimana konflik dalam kehidupan mulai berdatangan nampak, sehingga hal tersebut menjadi faktor bagi remaja untuk pentingnya belajar mengendalikan dan menyesuaikan diri dalam suatu kondisi yang dihadapi. Bentuk pengendalian dan penyesuaian diri dapat diartikan sebagai suatu tahapan yang menghubungkan perilaku dan mental individu. Individu akan menampakkan suatu usaha agar dapat memenuhi kebutuhan dan melewati masalah dalam kehidupannya. Hal tersebut akan membuat individu merasa berhasil untuk menghubungkan tuntutan diri dan harapan lingkungan sekitarnya (Desmita, 2009). 
Pengendalian dan penyesuaian diri memiliki beragam bentuk upaya dalam proses pencapaian nya. Kecerdasan spiritual merupakan salah satu bentuk penyesuaian diri yang dapat menuntun individu memiliki kehidupan yang berarti. Definisi kecerdasan spiritual sendiri ialah suatu bakat atau kemampuan yang berada pada diri manusia. Bakat atau kemampuan tersebut diibaratkan seperti suatu emas yang belum terlatih dan belum menjadi kepemilikan banyak orang. Oleh sebab itu, mendalami bakat dan kemampuan yang kita miliki merupakan suatu keharusan yang harus dikuasai agar lebih bertumbuh menjadi suatu kemampuan yang maksimal. Kecerdasan spiritual menjadi suatu harapan yang dapat dimanfaatkan dan diterapkan dalam aktivitas kehidupan agar mencapai suatu kebahagiaan (K. Khavari, 2000). Dalam literature lain pun juga dijelaskan bahwa segala sesuatu yang bersifat spiritual memiliki makna positif yang berdampak pada suatu tujuan hidup individu (Hasan, 2006).

Adapun yang dimaksud dengan kecerdasan spiritual merupakan gabungan dari dua kecerdasan yaitu, kecerdasan intelektual dan kecerdasan emosional. Kecerdasan spiritual disebut sebagai kecerdasan tertinggi, karena menjadi sumber dan landasan bagi kecerdasan lainnya (K. A. Khavari, 2000). Kecerdasan spiritual yang sering disingkat dengan sebutan SQ adalah kecerdasan seseorang untuk menunjukkan perilaku di kehidupan sehari-hari dalam konteks makna yang luas, kecerdasan seseorang dalam menyelesaikan persoalan nilai dan makna kehidupan, serta kecerdasan untuk menilai dan memilih tindakan serta jalan hidup yang lebih bermakna (Japar, 2014).

Pada tahap perkembangan seseorang, aspek pembelajaran keagamaan di usia anak-anak dapat mempengaruhi tingkat spiritualitas individu. Oleh karena itu, orang tua diharapkan mampu membimbing dan memperhatikan kegiatan keagamaan bagi anak-anaknya. Penelitian yang dilakukan oleh Bridges dalam (Aridhona, 2017) dengan subjek remaja telah menunjukkan hasil bahwa agama berefek positif dalam mengurangi perilaku menyimpang pada remaja seperti, kriminalitas, penggunaan zat dan obat-obatan terlarang, dan perilaku seksual bebas. Penelitian tersebut juga menunjukkan bahwa remaja dengan aspek keagamaan yang berkembang secara optimal cenderung berperilaku positif seperti, menerapkan dan memahami nilai-nilai moral, serta memiliki kepribadian mental yang baik.

Menurut (Wijayanati and Uyun, 2010) menemukan bahwa tingkat kecerdasan yang rendah pada mental remaja mempengaruhi keahlian untuk memecahkan berbagai permasalahan, mengontrol perbuatan dan kelakuan, serta membedakan tindakan yang benar dan salah. Selain itu, menurut (Yusuf, 2010) untuk menjauhi perilaku melenceng yang biasanya sering terjadi pada remaja di masyarakat, seperti berkelahi, pergaulan bebas, minum-minuman keras, merokok ganja dan membuat kerusakan pada lingkungkan masyarakat, perlu diadakannya kegiatan bimbingan agama.

Oleh karena itu, jika ingin mencapai peningkatan spiritual atau mendapatkan spiritual, perlu memiliki interpretasi yang mendalam tentang Islam dan meningkatkan pelaksanaan ajaran Islam. Individu harus sepenuhnya percaya, yakin, dan berserah diri dalam Islam. Islam merupakan agama yang mengajarkan kebenaran dan petunjuk untuk mencapai kehidupan yang bahagia di dunia dan di akhirat. Ketika individu memiliki kemampuan untuk menerapkan dan menjalankan ajaran Islam, mereka akan memperoleh kekuatan spiritual (Sejati, 2016).

Sebagai Individu yang mempunyai kecerdasan spiritual yang tinggi akan merasakan bahagia bagaimanapun keadaan pada dirinya, menilai positif dari setiap masalah yang dihadapinya serta mempunyai kekuatan untuk bertahan untuk melanjutkan hidup. Dalam Khavari memaparkan bahwa rumusan tes untuk menguji tingkat kecerdasan spiritual terlihat sederhana dan sudah umum diketahui oleh banyak orang. Namun, jika direfleksikan secara detail dan cermat tes kecerdasan spiritual sangat mendalam dan luar biasa. Ada tiga aspek kecerdasan spiritual yang mendasar, yaitu sudut pandang spiritual kepada Allah SWT, sudut pandang relasi sosial kepada sesama dalam kebersamaan dan kesejahteraan sosial, serta sudut pandang etika sosial pada kehidupan bermasyarakat (K. Khavari, 2000). 


\section{Metode}

\section{Partisipan}

Partisipan dalam alat ukur ini yakni Remaja Muslim di Indonesia yang berumur $12-24$ tahun. Adapun grade atau jenis pendidikan tidak menjadi penentu karakteristik partisipan, hanya saja partisipan diwajibkan beragama islam. Partisipan pun dapat berasal dari beragam daerah dan kota di Indonesia. Alat ukur ini memiliki tujuh ahli dalam penilaian penelitian dan mendapatkan partisipan sejumlah 104 remaja muslim.

\section{Prosedur Penelitian}

Metode penelitian yang kami gunakan adalah metode penelitian kuantitatif. Metode penelitian ini juga berdasar pada skala yang kita ambil yakni Skala Kecerdasan Spiritual sehingga atribut psikologi yang kami gunakan adalah kemampuan non-kognitif. Kecerdasan Spiritual memiliki 3 aspek dan 13 indikator, sehingga aitem yang kami cantumkan dalam blue print sebanyak 26 aitem. Sebelum melakukan proses penyebaran skala dilakukan terlebih dahulu penilaian skala dengan 8 rater kami. Adapun latar belakang dari 8 rater tersebut yakni, 3 dosen fakultas psikologi UINSA, 1 psikolog luar UINSA, 4 mahasiswa psikologi dari UINSA dan luar UINSA. Kami menyediakan skor 1 hingga skor 5 , skor 1 digunakan untuk aitem yang dirasa kurang jelas atau kurang sesuai dengan indicator, dan skor 5 diberikan bagi aitem yang memiliki kriteria sebaliknya. Aitem awal yang diserahkan pada 8 rater kami sebanyak 78 aitem. Setelah dilakukan eliminasi oleh 8 rater kami, aitem yang siap untuk diuji coba kan berjumlah 45 aitem.

Proses penyebaran skala dilakukan pada tanggal 22 April 2021 - 29 April 2021. Penyebaran skala tersebut dilakukan dalam bentuk format digital melalui media google form. Dalam format skala yang kami sebarkan, kami mencantumkan nama-nama peneliti, latar belakang dan tujuan penelitian melakukan penyebaran skala, bentuk kriteria partisipan, kebebasan pengisian skala, serta jaminan kerahasiaan data diri partisipan. Tim peneliti juga memberikan reward secara acak bagi 5 partisipan yang beruntung sebagai bentuk apresiasi kesediaan partisipan untuk melakukan pengisian skala pengukuran.

\section{Hasil dan Pembahasan}

\section{Penulisan Item}

Penulisan item pada Skala Kecerdasan Spiritual Remaja Muslim ini berpacu pada teori dari Khavari, yang mengatakan bahwa kecerdasan spiritual adalah kemampuan yang dimiliki oleh setiap individu yang harus dipahami dan diasah secara mendalam untuk memperoleh sebuah kebahagiaan yang abadi atau bermakna dalam kehidupan sehari-hari. Dalam hal ini kecerdasan spiritual merupakan gabungan dari dua kecerdasan yaitu, kecerdasan intelektual dan kecerdasan emosional. Teori kecerdasan spiritual menurut Khavari tersebut terdapat 3 aspek, diantaranya adalah : sudut pandang spiritual-keagamaan, sudut pandang relasi socialkeagamaan, serta sudut pandang etika social.

Dalam penyusunan item, pada awalnya peneliti menyusun aitem sebanyak 78 item yang terdiri dari item favorable dan unfavorable. Setelah itu direduksi dan dilakukan penyeleksian aitem sampai pada tahap reliablitas, yang mengahasilkan 24 item yang lolos dengan nilai reliabilitas tinggi, berikut rincian item yang lolos setelah tahap perhitungan reliabilitas pada skala kecerdasaran spiritual remaja muslim :

Tabel 1 : Item Skala Kecerdasan Spiritual Remaja Muslim

\begin{tabular}{|c|l|}
\hline No & \multicolumn{1}{|c|}{ Item } \\
\hline 1. & Dalam 24 jam saya selalu meluangkan waktu untuk berdoa. \\
\hline 2. & Saya selalu melaksanakan sholat fardhu 5 waktu. \\
\hline
\end{tabular}




\begin{tabular}{|c|l|}
\hline 3. & Jika saya ingin sesuatu, saya akan berikhtiar sekuat tenaga. \\
\hline 4. & Saya selalu memohon keselamatan di dunia dan akhirat kepada Allah. \\
\hline $\mathbf{5 .}$ & Saya percaya rencana Allah lebih baik dari rencana saya. \\
\hline $\mathbf{6 .}$ & Saya merasa lelah dengan ibadah yang harus saya lakukan. \\
\hline $\mathbf{7 .}$ & $\begin{array}{l}\text { Saya merasa hidup saya selalu dilimpahkan kesenangan daripada } \\
\text { kesedihan. }\end{array}$ \\
\hline $\mathbf{8 .}$ & Saya kurang puas dengan keadaan saat ini. \\
\hline $\mathbf{9 .}$ & Saya membantu orang lain, ketika hati saya terketuk. \\
\hline $\mathbf{1 0 .}$ & Saya merangkul orang-orang yang ada lingkungan sekitar. \\
\hline $\mathbf{1 1}$. & Saya bersedia merawat tanaman, karena mereka juga ciptaan Allah. \\
\hline $\mathbf{1 2 .}$ & Saya tidak peduli ada binatang apa pun di dekat saya. \\
\hline $\mathbf{1 3 .}$ & Saya sering menyisihkan uang/ barang untuk donasi bencana. \\
\hline $\mathbf{1 5 .}$ & $\begin{array}{l}\text { Saya terkadang bersikap acuh ketika terdapat pengamen yang } \\
\text { menghampiri saya. }\end{array}$ \\
\hline $\mathbf{1 6 .}$ & $\begin{array}{l}\text { Saya tidak pernah memainkan handphone saya ketika orang yang lebih } \\
\text { tua mengajak saya berbicara. }\end{array}$ \\
\hline $\mathbf{1 7 .}$ & Saya tidak pernah mengangkat kaki ketika makan. \\
\hline $\mathbf{1 8}$. & $\begin{array}{l}\text { Saya tidak pernah mengatakan tujuan yang sebenarnya apabila } \\
\text { berpamitan kepada orang tua. }\end{array}$ \\
\hline $\mathbf{1 9 .}$ & Saya selalu datang tepat waktu saat kerja kelompok. \\
\hline $\mathbf{2 0 .}$ & Saya selalu berkata sopan kepada orang yang lebih tua. \\
\hline $\mathbf{2 1 .}$ & Saya selalu mengumpulkan tugas dengan tepat waktu. \\
\hline $\mathbf{2 2 .}$ & $\begin{array}{l}\text { Ketika bertelpon saya selalu mengucapkan sapaan terlebih dahulu seperti } \\
\text { "Hallo" / "Assalamualaikum". }\end{array}$ \\
\hline $\mathbf{2 3 .}$ & Saya tidak membeda-bedakan dalam memilih teman. \\
\hline $\mathbf{2 4 .}$ & $\begin{array}{l}\text { Saya selalu bertutur kata yang baik dengan teman meskipun berbeda } \\
\text { keyakinan. }\end{array}$ \\
\hline $\mathbf{2 5}$ & Saya menghindari dari sikap keras dalam menyelesaikan masalah. \\
\hline $\mathbf{2 6 .}$ & Saya selalu bersikap emosi dalam menyelesaikan masalah. \\
\hline
\end{tabular}

\section{Validitas Isi}

Validitas isi merupakan validitas yang diestimasi melalui tahap pengujian terhadap kesesuaian atau relevansi isi tes dengan cara analisis rasional yang dilakukan oleh para ahli yang berkompeten melalui tahap expert judgment. Dalam hal ini yang dilihat adalah kesesuaian antara domain aitem yang dibuat dengan atribut yang hendak diukur.

Pada tahap expert judgment ini, kami memilih dan mendapatkan 8 orang ahli yang terdiri atas : dosen psikologi dan mahasiswa psikologi. Setelah tahap expert judgment, dilanjutkan dengan akumulasi perhitungan koefisien validitas isi aiken's $v$. Berdasarkan kriteria para ahli, maka batas nilai aiken's $v$ pada skala kecerdasan spiritual remaja muslim ini yaitu 0,75 . Melihat batas nilai aiken's $v$ tersebut terdapat 45 aitem yang lolos, yaitu aitem yang mendapatkan nilai diatas 0,75. Adapun aitem yang gugur atau tidak lolos sebanyak 33 aitem. Adapun item yang memenuhi standar nilai aiken's $v$ mempunyai nilai yang berkisar pada 0,75 hingga 1 . Kemudian aitem yang tidak memenuhi standar aiken's $v$ yaitu berkisar pada rentang 0,5 hingga 0,718.

Jika dilihat dari hasil komputasi aiken's $v$ diatas, maka ditemukan sebanyak 45 item yang siap untuk dilakukan uji coba atau field test. Dalam proses field test dilakukan dengan cara menyebarkan aitem menggunakan format digital yaitu google form. Hal ini disebarkan sejak tanggal 22 April 2021.

\section{Respon Objek terhadap Item}

Berdasarkan hasil validitas isi, akumulasi item yang diperoleh dapat menimbulkan respon yang beragam pada setiap item. Respon objek terhadap item digunakan untuk menentukan apakah item yang telah dibuat dan disebarkan kepada responden mampu membedakan 
penilaian ordinal pada skala. Dalam hal ini, skala yang digunakan yaitu likert. Sehingga data ordinal terdiri dari : sangat tidak setuju (STS), tidak setuju (TS), netral (N), setuju (S), dan sangat setuju (SS). Hasil respon objek terhadap 45 aitem yang telah disebarkan bisa dibilang cukup baik, serta mampu menentukan bias yang ditimbulkan dari responden.

Tabel 2 : Penilaian Model Likert

\begin{tabular}{cccc} 
Tanggapan & Deskripsi & F & UF \\
\hline STS & Sangat Tidak Setuju & 0 & 4 \\
TS & Tidak Setuju & 1 & 3 \\
N & Netral & 2 & 2 \\
S & Setuju & 3 & 1 \\
SS & Sangat Setuju & 4 & 0 \\
\hline
\end{tabular}

\section{Uji Reliabilitas}

Pada skala ini juga dilakukan uji reliabilitas, yaitu dimana untuk memberikan gambaran mengenai kemampuan item dalam mendeskripsikan variable yang hendak diukur. Skala kecerdasan spiritual remaja muslim ini menggunakan cronbach's alpha yang bernilai (rxx' > 0,856). Dalam skala ini sebanyak 41 item yang memenuhi nilai standard yaitu berkisar pada rentang 0,849 sampai 0,856. Adapun 4 item yang lainnya memiliki daya diskriminasi rendah, sehingga perlu dipertimbangkan atau dianggap gugur, karena memiliki nilai sebesar 0,857 sampai 0,863 .

\section{Pembahasan}

Dalam penelitian ini, skala kecerdasan spiritual remaja muslim disusun berdasarkan teori dari Khavari, yang mana dalam teori tersebut terdapat 3 aspek yaitu : sudut pandang spiritualkeagamaan, sudut pandang relasi social-keagamaan, serta sudut pandang etika social. Aspek pertama pada teori ini terdapat 4 indikator yang menggambarkan aspek pertama. Adapun aspek yang kedua terdapat 3 indikator, dan aspek yang ketiga terdapat 6 indikator. Setiap indicator memuat 2 aitem yang terdiri 1 item favorable dan 1 item unfavorable. Sehingga, skala kecerdasan spiritual remaja muslim ini berjumalah 26 item yang telah lolos dalam uji reliabilitas.

Dalam prosesnya, setelah aitem yang diujikan diberikan pada para ahli atau tahap expert judgment. Maka, dilanjut dengan perhitungan koefisien validitas aiken's $v$ yang menghasilkan nilai aiken's $v$ nya yaitu 0,856 . Aitem yang lolos pada tahap perhitungan aiken's $v$ akan diuji cobakan kepada 104 responden melalui format digital yaitu google form. Uji coba ini membutuhkan waktu 1 minggu yaitu awal penyebarannya pada tanggal 22 April 2021. Dalam penyebarannya, kami menggunakan model skala likert diantaranya : sangat tidak setuju (STS), tidak setuju (TS), netral (N), setuju (S), dan sangat setuju (SS). Adapun pemberian skor pada skala likert ini telah tercantum pada tabel 1.

Hasil validitas aiken's $v$ yaituu 0,856 yang dinilai cukup baik dengan rentang nilai 0,856 hingga 1 . Berdasarkan data tersebut, maka alat ukur yang tekah dirancang ini diharapkan dapat mengukur variable kecerdasan spiritual. Jumlah aitem yang masuk dalam tahap field test yaitu sebanyak 45 aitem. Dalam hal ini peneliti sudah melihat representasi indicator pada setiap item. Adapun tanggapan penilaian objek yang dihasilkan juga cukup baik dan dapat dikategorikan masuk kedalam distribusi normal yaitu 0,1,2,3,4.

Berdasarkan tahap uji reliabilitas menghasilkan nilai cronbach alpha sebesar 0,856. Dalam hal ini terdapat 41 item yang lolos, dan 4 item yang dipertimbangkan atau gugur. Item yang lolos direduksi menjadi 26 item yang tersebar dalam setiap indicator sebanyak 2 aitem. Melihat skala kecerdasan spiritual remaja muslim yang meghasilkan nilai alpha 0,856 maka skal 
ini layak digunakan sebagai instrument penelitian untuk menentukan seberapa besa tingkat spiritualitas pada remaja muslim.

Saran dalam penelitian ini yaitu terkait dengan pengambilan banyaknya sampel yang harus diperbanyak dalam proses field test. Sehingga hasil penelitian ini memiliki kredibilitas yang lebih baik. Selain itu, juga memperbanyak jumlah aitem yang hendak diberikan kepada expert judgment, yang bertujuan untuk menghindari kurangnya aitem yang gugur pada proses uji reliabilitas.

\section{Kesimpulan}

Ruang lingkup penelitian ini adalah skala kecerdasan spiritual remaja muslim yang telah diuji validitas isi. Mulai dari 78 item yang disusun berdasarkan aspek kecerdasan spiritual, kemudian direduksi menjadi 26 item yang valid dan direspon dengan baik. Berdasarkan skor alpha-cornbach sebesar 0,856 dapat disimpulkan bahwa skala kecerdasan spiritual remaja muslim ini layak untuk dijadikan instrumen pengukuran.

\section{Daftar Pustaka}

Aridhona, J. (2017) 'Hubungan Antara Kecerdasan Spiritual dan Kematangan Emosi dengan Penyesuaian Diri Remaja', Intuisi: Jurnal Psikologi Ilmiah, 9(3), pp. 224-233.

Desmita, D. (2009) Psikologi perkembangan peserta didik. Remaja Rosdakarya.

Hasan, A. W. (2006) 'SQ Nabi: Aplikasi Strategi Dan Model Kecerdasan Spiritual (SQ) Rasulullah Di Masa Kini', Yogyakarta: IRCiSoD.

Japar, M. (2014) 'Religiousity, Spirituality and Adolescents' Self-Adjustment.', International Education Studies, 7(10), pp. 66-73.

Khavari, K. (2000) Spiritual Intelligence (A Pratictical Guide to Personal Happiness). Canada: White Mountain Publications.

Khavari, K. A. (2000) The art of happiness. Penerbit Serambi.

Sejati, S. (2016) 'Perkembangan Spiritual Remaja dalam Perspektif Ahli', Jurnal Hawa: Studi Pengarus Utamaan Gender dan Anak, 1(1).

Wijayanati, A. and Uyun, Z. (2010) 'Pengaruh Kecerdasan Spiritual Terhadap Kenakalan Remaja: Studi Kasus Pada Siswa Klas 3 Sltp Muhammadiyah Masaran Sragen’.

Yusuf, S. (2010) 'Psikologi perkembangan anak dan remaja'. 